\title{
LOOKING INTO INTRICACIES OF POSITIVE ATTITUDES TOWARDS ENGLISH FOR ACADEMIC PURPOSES COURSES: A REVIEW OF LITERATURE AND ITS IMPLICATIONS
}

\author{
Dr. Roman Michaelan \\ SCE- Shamoon College of Engineering, 56 Bialik Street, Beer-Sheva, Israel \\ Email: roman.michaelan@gmail.com \\ Dr. Inna Smirnov-Oknin \\ Kaye Academic College of Education, 6 AzrielNizani, Beer-Sheva, Israel \\ Email: aoknin@gmail.com
}

\begin{abstract}
Against the backdrop of the spectacular dissemination of the English language worldwide, extensive and sustained efforts have been geared towards establishing and employing the most effective strategies that can lead to students' academic success in courses of English for academic purposes (EAP). This paper is aimed at offering literature review on attitudes to EAP courses in various higher education contexts and its implications. It considers a variety of reasons, both linguistic and non-linguistic, such as cultural aspects, attitude to the target language, various types of motivation and multicultural background of learners, as influential on students' positive attitudes towards learning English within the realm of higher education. The literature points to the crucial influence of those variables on students' positive attitudes. The paper concludes that there is a dire need for further research into the role of other aspects pertaining to teaching EAP courses that make the process more motivating and engaging for students.
\end{abstract}

Keywords: English for academic purposes, positive attitudes, motivation.

\section{Introduction}

There has been a consistent, evergrowing worldwide shift towards embracing English as a main language in the realm of higher education of nonEnglish speaking countries (NESC) over recent decades. The language has also gained an unprecedented predominance in various additional fields of modern society, and among them are science, technology, business and research. This accelerating change in the status of the language, which is widely deemed as a global lingua franca, is highly intertwined with globalization process by means of which it has been established (Qin \&Neimann, 2017). In that sense, the status bears some resemblance to that of Latin in 13th century European higher education institutions (HEI). It is worthy of note, however, that without detracting from the degree of prevalence of English within varied academic patterns, the probability that the latter will achieve a similar, to 
VS Publications

Alford Council of International English \& Literature Journal(ACIELJ)

Impact Factor:4.401(SJIF)An International Peer-Reviewed English Journal

www.acielj.com

Vol-3,Issue-2,2020

ISSN:2581-6500

Latin, status in scholarship and teaching is rather low (Altbach, 2013).

Viewed from this angle, the massive proliferation of the English language provided breeding ground for an unparalleled emergence of both English for Academic Purposes (EAP) and English for Specific Purposes (ESP) in the last century (Elhaj\& Ali, 2015). Being initially quite an insignificant branch of ESP, the former has swiftly evolved and has become a valuable facet in the sphere of research and English language teaching (Hyland, 2006). Drawing upon Hyland's (2006) definition, EAP is viewed as teaching the language with a view to assist "learners' study or research in that language" (p.1). The concept is generally found to be broad in scope and depth covering a whole spectrum of academic domains associated, inter alia, with research, examination and teaching (Flowerdew, 2013).

As to teaching EAP courses, the efficiency of the educational process is contingent upon and revolves around a number of noteworthy factors that need to be paid due attention as they carry much weight in creating a hospitable, favourable and productive atmosphere in such courses. Failure or success in building this type of learning environment are profound in their impact upon EAP learners' attitudes, either negative or positive, towards EAP courses. The following literature review is aimed at providing a meaningful glimpse into the positive attitudes across varied educational landscapes and sheds further light upon a variety of reasons, both linguistic and non- linguistic,

affecting

them.

2. Examining EAP Students' Positive Attitudes towards EAP Courses in NESC

\subsection{The Aspect of Culture and Attitude to the Target Language (Integrative Motivation)}

With emerging and mushrooming demand for having robustly proficient knowledge ofEnglish on the part of those who are involved in the existing educational landscapes in the global arena of higher education, considerable significance needs to be attached to the aspects bringing to the fore an increase, as well as a decline, in EAP students' motivation to take EAP courses with the view of strengthening their linguistic competence. With this need in mind, it is of importance to emphasize that the concept of motivation is regarded as one of the essential factors exerting influence upon language learning and upon accomplishment of success in this venture (Elhaj\& Ali, 2015). The emergence of motivation to acquire a language revolves around the extent to which students find the process meaningful and worthwhile for learning it in their society autonomously and continuously (Nakata, 2006). In this regard, it is deemed that learners' intention, their positive social attitude, to embrace the language of the society is linked to their embracing the society itself including its members, the speakers of the language, and the speakers' cultures (Morgan, 1993). Coming from this angle, the intention of the learners serves as a catalyst that strengthens their motivation to acquire the language, which in its turn, contributes to achieving success in this field (Morgan, 1993). 
VS Publications

Alford Council of International English \& Literature Journal(ACIELJ)

Impact Factor:4.401(SJIF)An International Peer-Reviewed English Journal

www.acielj.com

Vol-3,Issue-2,2020

ISSN:2581-6500

In that same vein, the aspect of the

culture of the target language and a favourable disposition of the taught towards the culture should never be overemphasized as it constitutes a strong incentive for learning the language. According to one of the findings of the study conducted among 210 students at King Saud University in Saudi Arabia (Hagler, 2014), a majority of the participants of both genders demonstrated a positive perception of the West. Additionally, holding positive views of the target language culture, and correspondingly, of the cultural background of the teachers should enhance the degree of interactions, their constructivity, between Western educators and their learners (Hagler, 2014).

The importance of the Western culture, and specifically Anglophone world culture, was also accorded due attention in another, described further below, study conducted at one of the universities in Yemen (Al-Tamimi\&Shuib, 2009). The participants, who were Petroleum Engineering students, expressed positive attitudes towards English, and a majority of them expressed similar attitudes and interest in the English speaking world being represented through the prism of English-language films.

Noted earlier ignited interest in the western culture is supposed to project a potential positive effect on learners' success in learning English. The idea that learners who have favourable attitudes towards a language, its speakers and their culture, tend to be more successful in their learning than those with negative attitudes is supported by a vast amount of research in the field. Among various manifestations of this connection is the one that emerged in the study that investigated attitudes to English among over 500 Japanese university students. Questionnaire-based data collection revealed positive attitudes of Japanese students towards the target language, its speakers and their culture: 94\% of students consider English as necessary for travel, $87 \%$ view English as crucial for communication with other nationalities, $67 \%$ mentioned that English is necessary for entertainment (Lafaye\&Tsuda, 2002).

Another study that is worth paying attention to in regard to culture and its effect on learners of English is the one conducted by Kizilpete (2000), which was aimed at investigating attitudes and motivation of Turkish students towards British and American culture. The results reveal that Turkish students have positive attitudes towards the target language culture that results in no in-class anxiety and, consequently, in better language learning.

The findings of the above studies are confirmed by Malallah's (2010) study on undergraduate students conducted in the Kuwait University. The current study examined students' attitudes and motivation to learn English and towards the target culture and its speakers. The findings support the hypothesis that having positive attitudes towards both the English language and its native speakers will positively affect their learning of the language.

Similar conclusions can be drawn from the study carried out among fifth year engineering students (72 participants) belonging to the Higher Technical School of Industrial Engineering Technical 
VS Publications

Alford Council of International English \& Literature Journal(ACIELJ)

Impact Factor:4.401(SJIF)An International Peer-Reviewed English Journal

www.acielj.com

Vol-3,Issue-2,2020

ISSN:2581-6500

University of Madrid (Bobkina, 2015).

The primary objective of the study was to identify engineering students' motivational and attitudinal orientations in learning English. To be specific, the researcher focused on identifying their attitude towards the language, its culture and its people. The data, collected through questionnaires, indicated that $82 \%$ of the students desire to contact with English speaking people in their native language. Integrative reasons were regarded by students as an important element of their motivation. The students' answers provide evidence of their interest regarding the culture of English-speaking countries, in particular, in such areas as science, economy, music and movies. It is worth mentioning that the majority of the students expressed interest towards different aspects of English culture (music, movies, science, traditions, contacting with English speakers etc.). They also express their desire to feel more integrated into English culture in addition to being able to contact with native speakers of the language.

Along similar lines, interestingly enough, a clear preference for learning the English language was expressed by participants (40 students) of a study held at a Cuban university (Van Splunder\&Dávila Pérez, 2018). In order to understand the relationship between learning and teaching English in Cuba and students' attitudes towards American culture and its people, it is crucial to relate to the complicated history of Cuba-U.S. relations. After the re-establishment of official diplomatic relations between the countries in 2015, learning English has become a priority in today's Cuba. This claim is supported by the study among 20 students from the English Department and 20 students from the Engineering Department. According to the data obtained from questionnaires, the university's students hold positive attitudes concerning English, which in turn enhance their motivation for learning the language.

In the light of the information presented above, the increased interest in the western culture is supposed to project a potential positive effect on learners' English attainment. In other words, students' interest in the language itself, its culture and the desire to communicate with the target language group results in a positive effect on learners' attitudes towards EAP courses.

\subsection{Instrumental, Utilitarian, Personal and Academic Reasons}

Without detracting from the importance and the merits of the abovementioned cultural background, there are other valuable factors that need to be assigned due weight. In that respect, it is worth noting mentioned earlier study that was carried out at Hadhramout University of Sciences and Technology (HUST) in Yemen (Al-Tamimi\&Shuib, 2009). The study was conducted with the aim of tracking Petroleum Engineering students' attitudes and motivation regarding learning English. The findings of the study indicated, inter alia, that the students laid special stress upon instrumental reasons for acquiring English, and among them were the ones related to academic and utilitarian reasons. Having means to carry one's tasks in a more efficient way may serve, for instance, as one of the examples of the former (Al-Tamimi\&Shuib, 2009). As to the latter, the authors pointed to 
VS Publications

Alford Council of International English \& Literature Journal(ACIELJ)

Impact Factor:4.401(SJIF)An International Peer-Reviewed English Journal

www.acielj.com

Vol-3,Issue-2,2020

ISSN:2581-6500

enabling a person 'to get a job easily' (p.

44). As for instrumentally motivated learners, they are interested in learning a language in order, for example, to 'pass an examination $\ldots$ because the educational system requires it' (Wilkins, as cited in AlTamimi\&Shuib, 2009, p. 32).

These findings echo and support other studies (Lafaye\&Tsuda, 2002; Bobkina, 2015) which prove that instrumental motivation may lead to a favourable attitude towards learning English as a foreign language. In this vein, $56 \%$ of the participants in the aforesaid study in Japan were motivated in their studies by exams (Lafaye\&Tsuda, 2002, p. 147). Similarly, instrumental motivation toward English language learning turned out to be the primary source of the motivation of 72 engineering students from the Higher Technical School of Industrial Engineering Technical University of Madrid. An overwhelming majority of the students of the University $(87.4 \%)$ claimed that the major instrumental motive for learning English revolved around the fact that it is a university requirement for getting the bachelor degrees (Bobkina, 2015). Along similar lines, personal reasons also play an important role in students' motivation: $82 \%$ of the participants indicated their need to contact in English with people all over the world, $83 \%$ pointed out the necessity of English while travelling abroad, and $61 \%$ underlined their interest in participating in English language cultural activities (Bobkina, 2015). The abovenoted examples are indicative of the continued need and aspiration of instrumentally motivated learners to be oriented towards studying the language with the view of benefiting from it (Elhaj\& Ali, 2015).

With regards to instrumental reasons lying behind students' favourable attitudes to learning the English language, it is worth paying heed to a study undertaken in the faculties of medicine of three universities in Sudan (Elhaj\& Ali, 2015). Among other things, the main thrust of the study was centred on investigating attitudes and motivation of 150 second year medical students regarding EAP courses: their materials and ascertaining the degree of the courses' impact upon the students' English language performance. What emerges unambiguously from the participants' responses is that instrumental motivation, inter alia, played a valuable role in triggering their interest in acquiring English. As one of the examples of such discerned from the collected data motivation, the researchers mention the one that is associated with the learners' view of the language as a means 'or requirement' (Elhaj\& Ali, 2015, p. 79) that provides a vital foundation for attaining their goal of finishing an academic degree. Another interesting instance of the motivation noted in the study brings to the fore an additional, linked to the pragmatic purpose, reason for the ignited interest to embark upon studying English. The collected data pointed to the aspect of future aim (e.g., building future career) as the one that strongly affected the willingness of the taught to be involved in the language learning. 
VS Publications

Alford Council of International English \& Literature Journal(ACIELJ)

Impact Factor:4.401(SJIF)An International Peer-Reviewed English Journal

www.acielj.com

Vol-3,Issue-2,2020

ISSN:2581-6500

Similarly, another study worthy of note is the one conducted in Al-Balqa Applied University (Abu-Snoubar, 2017). The research survey was based on a random sample of 176 students majoring in scientific faculties and faculties of Humanities. According to the obtained data, the vast majority of the participants view English positively owing to 'reasons related to finding better chances of education and careers as well as enhancing their self-esteem and self-image' (p. 28).

A valuable role of instrumental reasons as a significant determinant of students' attitudes in relation to learning English in EAP courses has also been found by other researchers ( Bobkina, 2015; Van Splunder\&Dávila Pérez, 2018).

The data collected by means of a questionnaire conducted at Universidad de Oriente, Santiago de Cuba, revealed that students held overwhelmingly positive attitudes with regards to English, which they perceive as highly significant for their career prospects: $90 \%$ of the Engineering students and $100 \%$ of language students considered English as very important for educational and professional prospects (Van Splunder\&Dávila Pérez, 2018). By the same token, an overwhelming majority of engineering students who participated in the above mentioned study carried out at the Higher Technical School of Industrial Engineering Technical University of Madrid were in favour of learning English (Bobkina, 2015): $98.6 \%$ of the respondents indicated that they need English for their professional career and future incorporation into the labour market. Importantly enough, $90 \%$ of the students affirmed that the knowledge of English would help them get a better-paid job, and $80 \%$ of them stated that a perfect command of English makes them competitive on the labour market.

\subsection{Degree and Type of Motivation: Intrinsic and Extrinsic Motivation}

In light of the above, it also needs to be highlighted that pursuant to the findings of the aforesaid study in Sudan (Elhaj\& Ali, 2015), students' willingness and energy to learn English vary depending on whether their motivation is extrinsic or intrinsic. As to the latter, intrinsically motivated learners are engaged 'in activities that enhance learning' (Pintrich\&Schunk, as cited in Okon, 2013, p. 8) and are interested in performing them owing to satisfactions that are inherent in the activities (Ryan \& Deci, 2000). This endeavour to acquire the language runs counter to the one revolving around learners' aspiration for external rewards (Ryan \& Deci, 2000). When learners accord the highest priority to earning the rewards (e.g., praise or grades) with a view to learn well, they are deemed to be extrinsically motivated $(\mathrm{Ng} \& \mathrm{Ng}$, 2015). Along with this, without detracting from the significance of instrumental motivation in language learning, it was pointed out that intrinsically motivated learners achieve the highest degree of success (Elhaj\& Ali, 2015).

However reasonable this claim may seem, there are other weighty grounds for considering it from a different angle as it confers an advantage to extrinsically motivated students. With this purpose in mind, it is worth looking into intricacies of a study carried out at Golestan University of Medical Sciences in Iran (Badeleh et al., 
VS Publications

Alford Council of International English \& Literature Journal(ACIELJ)

Impact Factor:4.401(SJIF)An International Peer-Reviewed English Journal

www.acielj.com

Vol-3,Issue-2 ,2020

ISSN:2581-6500

2017). The study was conducted among

441 EAP students who were studying in three medical colleges (i.e., medical, nursing and paramedical) of this higher education institution. Drawing upon the results of the study, the researchers pointed out that extrinsic motivation highly prevailed over intrinsic one with regards to the medical students. Additionally, the authors are of the opinion that it is worth paying due attention to implications pertaining to the stakeholders and EAP teachers. According to an implication of the study's findings, being deemed as a valuable factor, learners' motivational orientation needs to be attributed considerable significance in the field of learning and teaching L2 (Badeleh et al., 2017). Interestingly enough, students' educational degree exerted an essential influence on the type of their motivation. The results indicated that the participants studying for a higher educational degree expressed a clear preference for intrinsic motivation over extrinsic one to learn English. This preference for the type of motivation places an emphasis on considering the process of learning the language "as an instrument for achieving something like reading and translating scientific texts" (Badeleh et al., 2017, p.108).

To this can be added that the researchers are in favour of attaching a high value to some noteworthy aspects of the aforementioned field of language learning. According to them, the aspects of learners' learning styles and personalities should be taken into consideration by EAP teachers owing to their potential positive impact upon the educators' teaching methods.

\subsection{The Role of Teaching Methodology,} Language Proficiency and Academic Achievements

This brings us to the role of teaching methodology within the context of EAP courses as it is deemed to be a dominant factor in triggering negative attitude towards the type of courses (Kashefet al., 2014). Resorting to a suitable, for the taught, type of instruction may become a breeding ground for shaping a positive perception of EAP classes. In this regard, it is worth providing meaningful insights into a research study conducted among 80 students of engineering of an Iranian university (Kashefet al., 2014). The undergraduate students of Urmia University of Technology were chosen with an aim to explore whether a learning-centred instruction exerts an effect on the learners' reading attitude within the scope of EAP courses. Based upon the study's findings, the type of instruction appears to fall well within the domain of reading comprehension as opposed to the traditional teacher-centred approach. The effectiveness of the former approachmanifested itself in improvement of the participants' reading comprehension level. Another noteworthy, for the purpose of this paper, aspect of the abovementioned findings is related to its vital role as a primary driver of change in the students' attitudes pertaining to their academic reading skills. The aforenoted enhancement in the skills on the part of the taught creates a positive attitude among 
VS Publications

Alford Council of International English \& Literature Journal(ACIELJ)

Impact Factor:4.401(SJIF)An International Peer-Reviewed English Journal

www.acielj.com

Vol-3,Issue-2,2020

ISSN:2581-6500

the EAP practitioners towards this type of EAP courses.

Coming from this angle, it would be pertinent to point out that language proficiency of the learners can be a predictor of either positive or negative attitude on the subject of learning English. Students who are rated as highly proficient in the language show a higher positive attitude towards English than the medium and lower proficiency students. It was suggested that attitudes are more highly related to achievement owing to the complexity of 'the concepts of attitudes towards learning a second language' (Garner, as cited in Fatiha et al., 2014, p. 118). This view is supported by several research studies in the field and among them is the research conducted in the JinbunGakubu (Humanities) Department of Tokaigakuen University in Japan. According to the study, '85\% of the students were unhappy or very unhappy with their proficiency' (Lafaye\&Tsuda 2002 , p. 148), which in turn resulted in their negative attitude and 'visceral reaction' to English (p. 148). The finding should be viewed in the context of the stance taken by Japanese students regarding the language. There appears to be a general consensus among the students that 'an Anglophile goal [is] ... their guiding light, [and] Japanese students of English cannot accept their limited proficiency as natural and good enough for communication' (Honna, as cited in Lafaye\&Tsuda, 2002, p. 151).

Similar findings concerning the relationship between learners' degree of fluency in English and their attitude towards the language were revealed in a structured questionnaire that was distributed to 150 students from the faculties of Medicine in the aforesaid study in Sudan (Elhaj\& Ali, 2015). The results of the study 'confirmed the widelyheld view that positive attitudes towards the role of English strongly correlated with proficiency levels' (p. 82).

Another inference that a positive attitude toward learning English depends on students' sufficient language proficiency in English can be drawn from the research conducted by Doiz, Lasagabaster, and Sierra (as cited in Santos, Cenoz\&Gorter, 2018).Based on the result of the study, it was found that a number of students do not have a positive attitude with respect to the language due to their lack of confidence regarding their proficiency in English. It can be inferred from these findings that a positive attitude towards learning English depends on the sufficient language proficiency in English.

\subsection{Ascertaining the Degree of Students'} Motivation and their Attitude towards English within a Multicultural Academic Format

There is yet another valuable aspect falling within the scope of the present paper that should be taken into account considering the rich nature of existing higher education environments. The aspect carries much weight in multicultural academic patterns of nonAnglophone countries with learners speaking different languages as their mother tongues. The motivations on the part of the learners taking EAP courses along with the degree of their motivation with regards to English were amidst the aims of the study conducted on 194 EAP students of the university of Haifa 
VS Publications

Alford Council of International English \& Literature Journal(ACIELJ)

Impact Factor:4.401(SJIF)An International Peer-Reviewed English Journal

www.acielj.com

Vol-3,Issue-2,2020

ISSN:2581-6500

(Bensoussan, 2014). It is of importance to highlight that the study runs counter to the ones mentioned earlier in the paper. An eye-catching difference revolves around a peculiar nature of Israeli society consisting of a large spectrum of diverse religious and ethnic groups speaking various languages (e.g. Hebrew, Russian, Amharic, Arabic, etc.) as their mother tongues (Bensoussan, 2014). Being a multilingual country, Israel has two official languages: Arabic and Hebrew. The latter is the dominant one while the former 'is the native tongue of approximately $20 \%$ of the population' (Lawrence et al., 2017). Another noteworthy aspect of the country is that for native Hebrew speakers English is considered as the second language (L2). It is certainly not the case, however, with other sectors of the population: new immigrants and native minority groups (Bensoussan, 2014). In contrast to the native speakers of Hebrew, the representatives of these groups of Israel's population consider English as their third or even their fourth language (Bensoussan, 2014). Approached from this angle, it would be a largely myopic stance not to assign a high weight to the notable factor since researchers have yet to thoroughly look into 'the connections betweenstudents' motivations and their attitudes toward university studies and language learning in a multicultural university context' (Bensoussan, 2014, p. 1).

Keeping those constraints in view, it is pertinent to emphasize that the findings obtained from the study held in the Israeli university among students speaking different L1 languages are quite interesting given the specificity of the learners L1 background. Amongst the findings are the ones pertaining to academic achievements of the taught in reading comprehension, their attitudes towards English and language learning in general. As for the findings on academic success of the participants in EAP reading comprehension course, mean grades of native speakers of Hebrew are higher in comparison with the grades received by the students whose L1 is other than Hebrew. In regard to the participants' position concerning language learning and English, the results indicate that there are positive links among a number of factors, among which are 'EAP course grades ... attitude towards language learning and English' (Bensoussan, 2014, p. 16).

With that being said, it is worthy of note that there were considerable differences connected to the attitudes of native speakers of Hebrew and Arabic towards English. The differences revolved around characteristics dealing with integrative and instrumental motivations. Based on the results, Hebrew speakers were more positively oriented towards finding the language useful. The latter parameter corresponds to both integrative and instrumental nature of the motivation among EAP students described earlier in the paper.

\section{Implications and Recommendations}

However valuable and significant the above-mentioned studies may seem, it might be misleading to assume that they are sufficient to serve a solid basis for providing far-reaching and comprehensive recommendations with respect to a host of reasons lying behind holding positive attitudes on the part of EAP students 
VS Publications

Alford Council of International English \& Literature Journal(ACIELJ)

Impact Factor:4.401(SJIF)An International Peer-Reviewed English Journal

www.acielj.com

Vol-3,Issue-2,2020

ISSN:2581-6500

towards the type of courses in NESC. The current literature review provided a meaningful glimpse into the positive attitudes across varied educational landscapes towards EAP courses faced by non-native speakers of English and elaborated upon a variety of reasons, both linguistic and non-linguistic, affecting them. Some pedagogical implications for both administrators and practitioners can be suggested based on our comprehensive review.

1. Analysis / Identification of students' needs: It is fundamental for yielding appreciable results in the learning process to understand learners' needs, their personalities and learning styles. Once the factors are properly assessed, both the structure and educational materials used in EAP courses can be adapted and developed with the view of suiting them at various levels within various contexts.

2. Teaching materials: Contextual materials used for EAP courses should be relevant to different disciplines and be developed in collaboration with different faculties. Moreover, introducing authentic materials on a range of different topics can attract students and engender higher levels of motivation.

3. Teaching methods: Teachers are advised to employ teaching methods and strategies that are both purposeful and meaningful for the students in order to maximize the learning effectiveness and students' achievements. Learnercentred and interactive classes will allow for students' active involvement and, as a result, will provide a breeding ground for increase in motivation.

4. Enhancing students' self-esteem and self-image: It is highly suggested to lower levels of language anxiety through environmental support (both peer and teacher support) and build a trusting and reliable learning environment, there is a likelihood of increasing students' self-esteem and self-image.

5. Exposure to the Western culture: It is of importance to emphasize that consistent and continuous exposure to the Western culture in general and to Anglophone world culture in particular (entertainment, music, movies, etc.) may project positive effects on learners' attainment in the English language studied in EAP courses. It is also recommended to lay due emphasis upon exposing EAP students towards native speakers of the English language as it is deemed to be a serious incentive for the students to learn the target language and succeed in EAP courses.

6. Further internationalization and globalization processes:

Globalization and internationalization trends can help raise the awareness of the importance of English providing better chances for students' incorporation into the labour market. Additionally, the trends can play a vital role in attaining better-paid jobs with immense 
VS Publications

Alford Council of International English \& Literature Journal(ACIELJ)

Impact Factor:4.401(SJIF)An International Peer-Reviewed English Journal

www.acielj.com

Vol-3,Issue-2 ,2020

ISSN:2581-6500

potential to enhance professional prospects.

7. A valuable role of sufficient English proficiency: It is highly advisable to accord due attention to equipping EAP students with appropriate English skills since a good command of the language is of high importance in terms of generating a positive attitude towards learning the language.

\section{Suggestions for Further Research}

The current literature review attempted at providing a meaningful overview of the positive attitudes across varied educational landscapes towards EAP courses faced by non-native speakers of English and presented a variety of reasons, both linguistic and non-linguistic, influencing those attitudes. Even though some of the aspects mentioned below were investigated at some depth, we believe that further research into them can shed more light on reasons for positive attitudes towards EAP courses. Researchers have yet to thoroughly look intothe field of EAP students' attitudes toward language and language learning since it can furnish the needed data for curricula planners, teachers and instructors.

1. To conduct research to compare postgraduate students' attitudes to undergraduate students' attitudes towards EAP courses.

2. To study English language attitudes in areas other than education, among which are tourism, business, medicine, etc.
3. To explore the effect of the field of study on learners' attitudes towards EAP courses- differences in motivation across disciplines.

4. To investigate the effect of gender on learners' attitudes towards EAP courses.

5. To broaden the scope of research and to focus on policy makers and decisionmaking bodies, such, for example, as the Ministry of Education and the Council for Higher Education.

\section{Conclusion}

It is plausible to assume that an unparalleled predominance of the English language in the sphere of higher education of non-Anglophone countries will become even more pronounced in the near future. The manifestation of the hegemony is translated into practice in a variety of rapidly evolving educational contexts. In order to keep abreast with the ongoing changes, policy makers, decision-making bodies and educators should devote particular attention to an array of students' needs and challenges with the view of equipping them with necessary tools to fulfil the needs and overcome the challenges. With this purpose in mind, a high value should be assigned to creating a hospitable atmosphere for generating positive attitudes among learners with regards to English-oriented academic courses, such, for instance, as EAP courses. Successfully meeting this necessity by identifying factors forming the backbone of the attitudes can, inter alia, provide a wide room for manoeuvre 
VS Publications

Alford Council of International English \& Literature Journal(ACIELJ)

Impact Factor:4.401(SJIF)An International Peer-Reviewed English Journal

www.acielj.com

Vol-3,Issue-2,2020

ISSN:2581-6500

in uncovering the students' latent potential along with upholding the highest standards of varied higher education systems.

\section{References:}

[1]Abu-Snoubar, T. K. (2017). An evaluation of EFL students' attitudes toward English language learning in terms of several variables. International Journal of English Language Teaching, 5(6),1834.

[2]Altbach, P. G. (Ed.). (2013). The international imperative in higher education.Springer Science \&Business Media.

[3]Al-Tamimi, A., \&Shuib, M. (2009). Motivation and attitudes towards learning English: A study of petroleum engineering undergraduates at HadhramoutUniversity of Science and Technology. GEMA Online Journal of Language Studies, 9(2), 29-50.

[4]Badeleh, M. T., Enayat, M. J., Badeleh, M., \&Yanesari, H. S. (2017). The type and reliable predictors of motivation: A case of Iranian EAP learners. International

Journal of English Language \& Translation Studies, 5(1),101-110.

[5]Bensoussan, M. (2014).Motivation and English language learning in a multicultural university context.Journal of Multilingual and Multicultural Development,18. DOI:10.1080/01434632. 2014.936874

[6]Bobkina, J. (2012). Motivation and attitudes towards learning English: A study of engineering undergraduates at the Technical University of Madrid.Conference Paper.

[7]Elhaj, A. A., \& Ali, N. A. (2015). Effects of Attitudinal Factors on Language
Performance among Sudanese EAP

Medical Students.English Linguistics

Research, 4, 69-87.

[8]Fatiha, M., Sliman, B., Mustapha, B., \&Yahia, M. (2014). Attitudes and motivations in learning English as a foreign language. International Journal of Arts \& Sciences, 7(3), 117-128.

[9]Flowerdew, J. (Ed.). (2013). Academic discourse, Routledge.

[10]Hagler, A. (2014). A study of attitudes toward Western culture among Saudi university students.Learning and Teaching in Higher Education: Gulf Perspectives, 11(1), 1-14.

[11]Hyland, K. (2006). English for academic purposes: An advanced resource book.Routledge.

[12]Kashef, S. H., Pandian, A., \&Khameneh, S. M. (2014). Toward a learning-centered EAP instruction: An attempt to change students' reading attitude. Theory \& Practice in Language Studies, 4(1), 39-45.

[13]Kizilepte, Z. (2000). Attitudes and motivation of Turkish EFL students toward second

language learning. International Journal of Applied Linguistics, 129(1), 141-168.

[14]Lafaye, B. E., \&Tsuda, S. (2002). Attitudes towards English language learning in higher education in Japanese society.Intercultural Communication Studies,

XI(3), 145-161.

[15]Lawrence, C., Inbar-Lourie, O., \& Weinberg, L. (2017).A handbook for English medium instruction in institutions of higher education in Israel: English as a cornerstone of sustainable technology and research. ECOSTAR. 
VS Publications

Alford Council of International English \& Literature Journal(ACIELJ)

Impact Factor:4.401(SJIF)An International Peer-Reviewed English Journal

www.acielj.com

Vol-3,Issue-2,2020

ISSN:2581-6500

[16]Malallah, S. (2010). English in an

Arabic environment: Current attitudes to

Englishamong Kuwait University students.

International Journal of Bilingual

Education and Bilingualism, 3(1), 19-43.

http://dx.doi.org/10/1080/1367005000866

7698

[17]Morgan, C. (1993). Attitude change and foreign language culture learning.

LanguageTeaching, 26(2),

63-75.

http://dx.doi.org/10.1017/S026144480000

7138

[18]Nakata, Y. (2006). Motivation and experience in foreign language learning. Peter Lang.

[19]Ng, C. F., \& Ng, P. K. (2015).A review of intrinsic and extrinsic motivations of ESL learners.International Journal of Languages, Literature and Linguistics, 1(2),98-105.

[20]Okon, K. (2013). Teaching English effectively: With special focus on learners' interests. Anchor Academic Publishing, Hamburg.

[21]Qin, L., \&Neimann, T. D. (2017). Fostering English learners' intercultural competenceandmulticultural awareness in a foreign language university in northeastern China.In Wang, V. C. X. (Eds.), Encyclopedia of strategic leadership and management (pp. 890913). IGI Global.

[22]Ryan, R. M., \& Deci, E. L. (2000). Intrinsic and extrinsic motivations: Classic definitions and new directions', Contemporary Educational Psychology, 25(1), 54- 67.

[23]Santos, A., Cenoz, J., \&Gorter, D. (2018). Attitudes and anxieties of business and education students towards English: Some data from the Basque country'.Language, Culture and Curriculum, 31(1), 94-110, DOI: 10.1080/07908318.2017.1350189

[24]Van Splunder, F., \&Dávila Pérez, G. (2018).Attitudes towards English in Cubanhigher education.Recent developments and challenges. In 4th International Conference on Higher Education

Advances,(HEAd'18) (pp.

$125-$ 132).Universitat

Politecnica de Valencia, Valencia. 